University of Nebraska - Lincoln

DigitalCommons@University of Nebraska - Lincoln

\title{
Analysis of Human Skin Emanations by Gas Chromatography/ Mass Spectrometry. 2. Identification of Volatile Compounds That Are Candidate Attractants for the Yellow Fever Mosquito (Aedes aegypti)
}

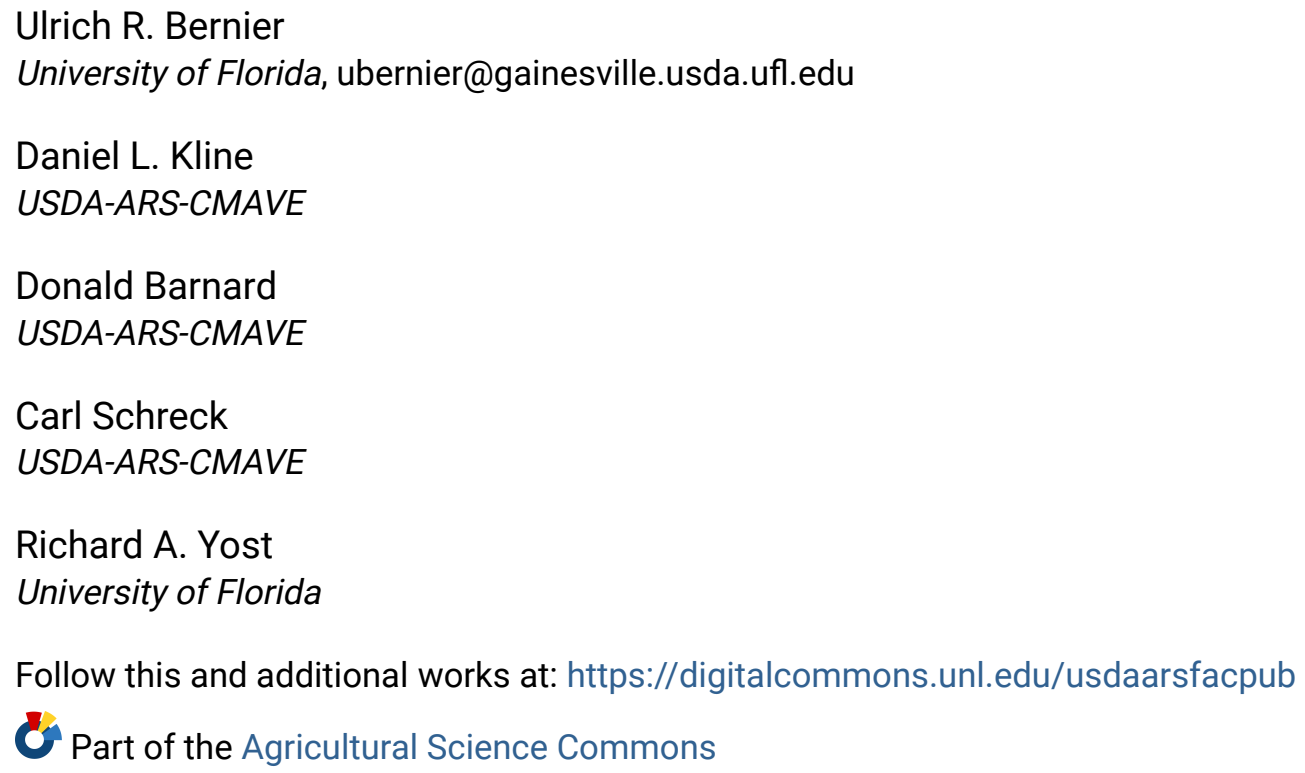

Bernier, Ulrich R.; Kline, Daniel L.; Barnard, Donald; Schreck, Carl; and Yost, Richard A., "Analysis of Human Skin Emanations by Gas Chromatography/Mass Spectrometry. 2. Identification of Volatile Compounds That Are Candidate Attractants for the Yellow Fever Mosquito (Aedes aegypti)" (2000). Publications from USDA-ARS / UNL Faculty. 946.

https://digitalcommons.unl.edu/usdaarsfacpub/946

This Article is brought to you for free and open access by the U.S. Department of Agriculture: Agricultural Research Service, Lincoln, Nebraska at DigitalCommons@University of Nebraska - Lincoln. It has been accepted for inclusion in Publications from USDA-ARS / UNL Faculty by an authorized administrator of DigitalCommons@University of Nebraska - Lincoln. 


\title{
Analysis of Human Skin Emanations by Gas Chromatography/Mass Spectrometry. 2. Identification of Volatile Compounds That Are Candidate Attractants for the Yellow Fever Mosquito (Aedes aegypti)
}

\author{
Ulrich R. Bernier, ${ }^{*, t, \neq}$ Daniel L. Kline,,$^{\S}$ Donald R. Barnard, ${ }^{\S}$ Carl E. Schreck,, , and Richard A. Yost ${ }^{\dagger}$ \\ University of Florida, Department of Chemistry, P.O. Box 117200, Chemistry Laboratory Building, Gainesville, Florida 32611, \\ and United States Department of Agriculture-Agricultural Research Service, Center for Medical, Agricultural, and Veterinary \\ Entomology, 1600 SW 23rd Drive, Gainesville, Florida 32608
}

\begin{abstract}
Volatile compounds emanated from human skin were studied by gas chromatography/ mass spectrometry (GC/ MS). The purpose of this study was to identify compounds that may be human-produced kairomones which are used for host location by the mosquito, Aedes aegypti (L.). The procedure used to collect volatiles was chosen because of prior knowledge that attractive substances can be transferred from skin to glass by handling. Laboratory bioassays have shown that the residuum on the glass remains attractive to mosquitoes until the compounds of importance evaporate. The sampling and analytical procedures modeled the above-cited process as closely as possible except that the evaporation of compounds from the glass surface was accomplished by thermal desorption from glass beads in a heated GC injection port. This made possible the solventless injection of volatiles onto the column. The compounds were cryofocused on the head of the column with liquid nitrogen prior to GC separation. A single stage of mass spectrometry on a triple quadrupole instrument was used for mass analysis. A combination of electron ionization and pulsed positive ion/negative ion chemical ionization modes on two different GC columns (one polar, one relatively nonpolar) was used to identify most of the 346 compound peaks detected by this technique.
\end{abstract}

M osquitoes are nuisance pests to both livestock and humans. In addition to causing annoyance, mosquitoes are vectors of the disease agents that cause malaria, viral encephalitis, dengue fever, filariasis, and dog heartworm. ${ }^{1,2}$ The reason for conducting this work is to better understand host attraction by identifying the volatile compounds emanated by humans. The mosquito species

\footnotetext{
* Corresponding author: (phone) 352-374-5917; (fax) 352-374-5922; (e-mail) ubernier@gainesville.usda.ufl.edu.

+ University of Florida.

₹ Current affiliation is USDA-ARS-CM AVE.

$\S$ USDA-ARS-CM AVE

" Deceased July 22, 1998.

(1) James, A. J. Science (Washington, D.C.) 1992, 257, 37-8.

(2) Gillett, J. D. M osq. News 1979, 39, 221-9.
}

10.1021/ac990963k CCC: $\$ 19.00 \quad$ C 2000 American Chemical Society Published on Web 12/23/1999 that is targeted by this study is the yellow fever mosquito, Aedes aegypti (L.), which transmits yellow fever, dengue fever, and dengue hemorrhagic fever. ${ }^{3}$

Common approaches to mosquito control and control of the diseases that they transmit employ the use of chemical insecticides for area-wide mosquito abatement and repellents for personal protection. Because of insecticide resistance in mosquitoes and concern with pollution of the environment with pesticides, 4,5 there has been an increased emphasis on the development of alternative mosquito control technologies. The use of attractant-baited traps/ targets is one promising technology currently being considered for this purpose. M osquitoes use attractants to locate their mates, find hosts for blood feeding, find nectar sources, and locate resting and oviposition sites. Host attractants appear to offer the most immediate promise for utilization in traps/targets. However, effective utilization of attractants for mosquito control requires an understanding of the mechanisms that attract mosquitoes to humans and animals. Ultimately, improved understanding of attraction may also lead to the design of better repellents.

Mosquito Attraction Stimuli. Current knowledge indicates that attraction to (or repulsion from) a potential host involves a behavioral response by the female mosquito to one or more host stimuli, which include visual cues, ${ }^{6-13}$ moisture, ${ }^{6-8,14,15}$ heat, $^{6-8,14}$ carbon dioxide, ${ }^{6-9,11,13-26}$ and other host chemical emanations. ${ }^{6-9,11,14,16,19-26}$ Although sound (specifically wing-beat frequency) is not a stimulus for host location, it is a short-range attractant for orientation of males to females for mating. ${ }^{6,27,28}$

(3) Hoelterhoff, M. SmartM oney 1994, 3, 128-32.

(4) Kline, D. L. J. Am. M osq. Control Assoc. 1994, 10, 253-7.

(5) Rathburn, C. B. Wing Beats 1990, 1, 12-3.

(6) M clver, S. B. J. Med. Entomol. 1982, 19, 489-535.

(7) Takken, W. Insect Sci. Its Appl. 1991, 12, 287-95.

(8) Sutcliffe, J. F. J. Am. M osq. Control Assoc. 1994, 10, 309-15.

(9) Bidlingmayer, W. L. J. Am. M osq. Control Assoc. 1994, 10, 272-9.

(10) Allan, S. A. J. Am. M osq. Control Assoc. 1994, 10, 266-71.

(11) Foster, W. A.; Hancock, R. G. J. Am. M osq. Control Assoc. 1994, 10, 28896

(12) Browne, S. M .; Bennett, G. F. J. Med. Entomol. 1981, 18, 505-21.

(13) Schreck, C. E.; Gouck, H. K.; Posey, K. H. M osq. News 1972, 32, 496-501.

(14) Price, G. D.; Smith, N.; Carlson, D. A. J. Chem. Ecol. 1979, 5, 383-95.

(15) Takken, W.; Knols, B. G. J.; Otten, H. Ann. Trop. M ed. Parasitol. 1997, 91 Suppl. 1, S119-20. 
Chemical emanations, including and in addition to carbon dioxide, appear to be the most important mechanism used by mosquitoes to locate their hosts.

Unfortunately, few specific host chemical emanations have been identified definitively as mosquito attractants. The compound L-lactic acid was identified as a chemical attractant for Ae. aegypti in 1968 from an acetone washing of human skin. ${ }^{29}$ It has also been shown that a synergistic attraction response can be produced by combining L-lactic acid with carbon dioxide. ${ }^{29,30}$ Since the discovery of Ae. aegypti attraction to lactic acid, studies of compounds structurally similar to lactic acid for mosquito attraction have produced mixed results. ${ }^{20}$

The compound 1-octen-3-ol (octenol), present in cow's breath, ${ }^{31}$ has been identified as an attractant for some species of mosquitoes. Although the response to octenol by itself is not as great as the response to carbon dioxide by itself, synergism has been demonstrated when both are employed together as attractants for some species of mosquitoes. ${ }^{21-25}$ In addition to lactic acid and octenol, other yet-unidentified compounds that emanate from the skin have been shown to play a role in the attraction of Ae. aegypti to humans. ${ }^{32}$ Therefore, it is believed that the examination of human skin emanations will provide the necessary information to further define the chemical cues by which mosquitoes locate human hosts.

Analysis of Human Odor and Perspiration. Studies of body odor, particularly those odors associated with perspiration, yield knowledge of compounds present on the skin, but not necessarily about the volatiles that are of importance to host-seeking behavior. Perspiration, comprised mainly of water, is a dilute solution of compounds containing salts, involatile compounds, as well as small amounts of volatiles. Analysis by combined liquid chromatography/ mass spectrometry (LC/MS) has detected the presence of lactic acid (lactate is a byproduct of exercise), urea, and various amino acids (phenylalanine, leucine, valine, and alanine). ${ }^{33} \mathrm{How}$ ever, the vapor pressures of amino acids are presumably too low to permit such compounds to be present at levels detectable by mosquito chemosensilla.

(16) Gillies, M. T. Bull. Entomol. Res. 1980, 70, 525-32.

(17) Kline, D. L. J. Am. M osq. Control Assoc. 1994, 10, 280-7.

(18) Schreck, C. E.; J ames, J. M osq. N ews 1968, 28, 33-8.

(19) Schreck, C. E.; Gouck, H. K.; Posey, K. H. M osq. News 1970, 30, 641-5.

(20) Carlson, D. A.; Smith, N.; Gouck, H. K.; Godwin, D. R. J. Econ. Entomol. 1973, 66, 329-31.

(21) Takken, W.; Kline, D. L. J. Am. M osq. Control Assoc. 1989, 5, 311-6.

(22) Kline, D. L.; Takken, W.; Wood, J. R.; Carlson, D. A. M ed. Vet. Entomol. 1990, 4, 383-91.

(23) Kline, D. L.; Wood, J. R.; Cornell, J. A. J. Med. Entomol. 1991, 28, 254-8.

(24) Kline, D. L.; Dame, D. A.; M eisch, M. V. J. Am. M osq. Control Assoc. 1991, 7, 165-9.

(25) Kemme, J. A.; van Essen, P. H. A.; Ritchie, S. A.; Kay, B. H. J. Am. M osq. Control Assoc. 1993, 9, 431-5.

(26) Takken, W.; Dekker: T.; Wijnholds, Y. G. J. Insect Behav. 1997, 10, 395407.

(27) Belton, P. J. Am. Mosq. Control Assoc. 1994, 10, 297-301.

(28) M ankin, R. W. J. Am. M osq. Control Assoc. 1994, 10, 302-8.

(29) Acree, F.; Turner, R. B.; Gouck, H. K.; Beroza, M.; Smith, N. Science (Washington, D.C.) 1968, 161, 1346-7.

(30) Smith, C. N.; Smith, N.; Gouck, H. K.; Weidhaas, D. E.; Gilbert, I. H.; M ayer, M. S.; Smittle, B. J .; Hofbauer, A. Ann. Entomol. Soc. Am. 1970, 63, 76070.

(31) Hall, D. R.; Beevor, P. S.; Cork, A.; Nesbitt, B. F.; Vale, G. A. Insect Sci. Its Appl. 1984, 5, 335-9.

(32) Schreck, C. E.; Smith, N.; Carlson, D. A.; Price, G. D.; Haile, D.; Godwin, D. R. J. Chem. Ecol. 1981, 8, 429-38.
One requirement for mosquito attraction is that the attractant is sufficiently volatile for both short- (typically less than $3 \mathrm{~m}$ ) and long-range (thought to be up to $60 \mathrm{~m}$ ) detection by mosquitoes to occur. Human breath does excite and attract Ae. aegypti, and the analysis of breath has led to the identification of over 100 compounds. ${ }^{34}$ There is some overlap of compounds identified in breath with those from skin; it should be noted, however, that although both skin emanations and breath attract mosquitoes, entirely different processes generate these compounds and the overall compositions are very dissimilar. Previous studies were conducted to identify the odor components of human perspiration, as well as total effluents produced by humans in an enclosed environment; $35-40$ over 260 compounds, spanning a wide range of compound classes, have been reported.

Experiments comparing isopropyl alcohol extracts from the fingers of adults and children have been briefly discussed in the literature. ${ }^{35}$ This method of collection was reported to provide more material than extraction of fingerprints from glass; however, the time delay regarding collection of fingerprints from glass was not reported. Sampling from glass, as was done in the current study, provides a discriminating benefit with respect to attractant analysis. It is known that at least some of the attractive compounds will be transferred to glass, and these compounds will evaporate, thus enabling orientation of mosquitoes to the glass. The use of glass beads is believed to allow for preferential concentration of oily/ waxy residues while minimizing collection of aqueous perspiration. ${ }^{41}$

Other recent work has emphasized the identification of skin emanations that attract mosquitoes, including Ae. aegypti. ${ }^{41,42}$ One method isolated active components from fractionated ethanol washing of human skin. ${ }^{42}$ Lactic acid was confirmed to play a role with at least two additional compounds used in the mosquitohost attraction process. We have previously described a different approach, identifying primarily the volatile to semivolatile components, where these compounds are first transferred to glass then desorbed back off of the glass in the injection port of a gas chromatograph. ${ }^{41}$ Recent progress has been made with attraction of A nopheles gambiae Giles, an important malaria vector. ${ }^{43}$ Observations that this species (and other Anophelines) has preferential body locations from which it takes blood meals has recently led

(33) Yokoyama, Y.; Aragaki, M .; Sato, H.; Tsuchiya, M . Anal. Chim. Acta 1991 246, 405-11.

(34) Krotoszynski, B.; Gabriel, G.; O'N eill, H.; Claudio, M. P. A. J. Chromatogr Sci. 1977, 15, 239-44.

(35) Noble, D. Anal. Chem. 1995, 67, 435A-8A

(36) Zeng, X.-N .; Leyden, J. J .; Lawley, H. J.; Sawano, K.; N ohara, I.; Preti, G. J. Chem. Ecol. 1991, 17, 1469-91.

(37) Zeng, X.-N .; Leyden, J. J.; Brand, J. G.; Spielman, A. I.; M cGinley, K. J.; Preti, G. J. Chem. Ecol. 1992, 18, 1039-55.

(38) Conkle, J. P.; M abson, W. E.; Adams, J. D.; Zeft, H. J.; Welch, B. E. Aerospace Med. 1967, 38, 491-9.

(39) Ellin, R. I.; Farrand, R. L.; Oberst, F. W.; Crouse, C. L.; Billups, N. B.; Koon, W. S.; M usselman, N. P.; Sidell, F. R. J. Chromatogr. 1974, 100, 137-52.

(40) Sastry, S. D.; Buck, K. T.; Janák, J.; Dressler, M.; Preti, G. In Biochemical Applications of M ass Spectrometry, First Supplementary Volume; Waller, G. R., Dermer, O. C., Eds.; J ohn Wiley \& Sons: Chichester, England, 1980; pp 1086-129.

(41) Bernier, U. R.; Booth, M. M.; Yost, R. A. Anal. Chem. 1999, 71, 1-7.

(42) Geier, M.; Sass, H.; Boeckh, J. In Mosquito-Host Interactions-Ciba Foundation Symposium 200; Bock, G. R., Cardew, G., Eds.; John Wiley \& Sons: Chichester, England, 1996; pp 132-48.

(43) Knols, B. G. J.; M eijerink, J. Sci. Med. (NY) 1997, 4, 56-63. 
to a focus on foot odors. ${ }^{44}$ This has resulted in the discovery that Limburger cheese is an attractant, further leading to the examination of bacteria-produced acids as mosquito attractants. ${ }^{43,45,46}$ Additionally, incubated sweat was shown to be attractive to An. gambiae sensu stricto and that fresh sweat was not attractive. ${ }^{47}$

The purpose of this manuscript is to report the identities of human skin emanations that are desorbed from handled glass and then analyzed using the method described by us in a previous paper. ${ }^{41}$ The results reported herein provide the foundation for the next manuscript in this series, in which a comparison is made of emanations from hosts for which Ae. aegypti has a markedly different attraction.

\section{EXPERIMENTAL SECTION}

Sample Collection, Loading, and Cryofocusing. Experiments used two to five 2.9-mm-diameter glass beads handled by one of four human male subjects, 26, 49, 52, and 61 years in age. The two oldest subjects were tested 16 times each. Each subject handled beads for a total of eight analyses with electron ionization (EI) and eight by chemical ionization (CI). The eight analyses by each ionization mode consisted of four analyses using a HP5 column (Hewlett-Packard, Atlanta, GA) and four using a HP-FFAP column (Hewlett-Packard). The 49-year-old subject was tested on five consecutive days, using both $\mathrm{EI}$ and $\mathrm{Cl}$ modes, and only on an HP-FFAP column, for a total of 10 analyses. The 26-year-old subject provided handled beads for two $\mathrm{EI}$ and two $\mathrm{Cl}$ analyses on each of the two columns employed, for a total of eight analyses. Volunteer subjects were not given any special instructions with regard to diet, handwashing, or application of normal toiletries prior to arriving at the laboratory. However, all subjects used the same soap to wash their arms and forearms in the laboratory when they arrived. The subjects then handled $15-25$ beads when their hands were completely dry, 10-20 min after washing. The glass beads were rubbed in the palms and on the backs of the hands by a subject for 10-15 min prior to placing them into an insert. The gloved author held the insert while the ungloved subject placed the beads in the insert.

After loading the beads into a Varian 3400 GC (Varian, Walnut Creek, CA) fritted glass injection insert, the insert was replaced, reversed from normal configuration, in the injection port. The cap, septum, and needle guide were then restored to seal the injection port. The frit kept the beads from dropping down onto the column entrance and provided a means for volatile emanations to be loaded onto the column; the column entrance extended up into the injector insert and was located just below the frit. The injection port was operated in an entirely splitless mode for the duration of the experiment, providing only one exit for volatiles, i.e., through the column. This configuration allows for as many as 12 beads to be placed between the frit (located approximately halfway down the insert) and the GC septum sealing the injection port. Throughout the loading process, the injection port was held at $25{ }^{\circ} \mathrm{C}$ to minimize sample loss from evaporation and the head pressure of helium was set to 0 psig to allow for proper alignment

(44) Dejong, R.; Knols, B. G. J. Experientia 1995, 51, 80-4.

(45) Knols, B. G. J.; van Loon, J. J. A.; Cork, A.; Robinson, R. D.; Adam, W.; M eijerink, J.; Dej ong, R.; Takken, W. Bull. Entomol. Res. 1997, 87, 1519.

(46) Dejong, R.; Knols, B. G. J. Acta Trop. 1995, 59, 333-5.

(47) Braks, M. A. H.; Takken, W. J. Chem. Ecol. 1999, 25, 663-72. of the septum and prevent premature migration of volatiles past the intended point of cryofocusing on the column.

The cryofocusing process involved heating glass beads in the GC injection port to desorb volatiles. B efore increasing the helium head pressure, liquid nitrogen $\left(\mathrm{LN}_{2}, \mathrm{bp}-196{ }^{\circ} \mathrm{C}\right)$ was placed in a 12-0z Styrofoam cup. The cup was placed in the oven such that the approximately $8 \mathrm{~cm}$ of column could be looped in the cup about $15 \mathrm{~cm}$ below the point where the column enters the oven from the injection port. The helium pressure was then increased to $20 \mathrm{psig}$, and the initial desorption phase started. This entailed loading a program to ramp the injection port from 25 to $250{ }^{\circ} \mathrm{C}$ over $7.5 \mathrm{~min}$ and then holding at $250^{\circ} \mathrm{C}$ for $2.5 \mathrm{~min}$. Throughout the cryofocusing phase, the $\mathrm{GC}$ oven was set at $25^{\circ} \mathrm{C}$ and the transfer line set at $40^{\circ} \mathrm{C}$. Liquid nitrogen was added to the cup as necessary during this 10-min cryofocusing phase. When available, standards were analyzed by direct inlet probe (limited to solids and confirmation by mass spectrum only) or were injected $(0.5 \mu \mathrm{L}$ of a $100-150 \mathrm{ng} / \mu \mathrm{L}$ solution in methylene chloride or hexane) on the HP5 column under the same conditions as the glass bead experiments.

Chromatographic Parameters. After the completion of cryofocusing, a new program was loaded from the computer to the Varian $3400 \mathrm{GC}$. Once the oven temperature reached equilibrium at the start temperature of the temperature ramp program, the cup containing liquid nitrogen was removed. Analyses involving the comparison of subjects were performed with different ramp programs, depending upon the column employed. The columns were a $25 \mathrm{~m} \times 0.20 \mathrm{~mm}$ i.d. HP5 FSOT column $\left(d_{\mathrm{f}}=0.33 \mu \mathrm{m}\right)$ or a HP-FFAP $25 \mathrm{~m} \times 0.20 \mathrm{~mm}$ i.d. FSOT column $\left(\mathrm{d}_{\mathrm{f}}=0.33 \mu \mathrm{m}\right)$. For experiments conducted with the HP5 column (35-min run time), the $\mathrm{GC}$ ramp consisted of a 1.0-min hold at $40^{\circ} \mathrm{C}$ followed by a 10.6-min ramp at $17{ }^{\circ} \mathrm{C} / \mathrm{min}$ and then a hold at $220^{\circ} \mathrm{C}$ for $23.4 \mathrm{~min}$. The transfer line was concurrently ramped from 50 to $220{ }^{\circ} \mathrm{C}$ at $20^{\circ} \mathrm{C} / \mathrm{min}$ over $8.5 \mathrm{~min}$ and held at $220^{\circ} \mathrm{C}$ for the remainder of the analysis. The ramp program for the FFAP column (45-min run time) consisted of a 1.0-min hold at $40{ }^{\circ} \mathrm{C}$ followed by a $17.7-\mathrm{min}$ ramp at $11^{\circ} \mathrm{C} / \mathrm{min}$ to $235^{\circ} \mathrm{C}$ and then a hold for $26.3 \mathrm{~min}$ at this temperature. The transfer line was concurrently ramped from 50 to $236^{\circ} \mathrm{C}$ at $23^{\circ} \mathrm{C} / \mathrm{min}$ for $8.1 \mathrm{~min}$ and held at $236^{\circ} \mathrm{C}$ for the remaining $36.9 \mathrm{~min}$. The column and transfer line were held at their final temperatures for $10.0 \mathrm{~min}$ after the recording of data, to bake off any high-boiling components prior to the next analysis.

Mass Spectrometric Parameters. The TSQ70 triple quadrupole mass spectrometer (Finningan-M AT, San J ose, CA) was operated using only a single stage of mass detection. Both EI and pulsed positive ion/ negative ion chemical ionization (PPINICI) 48 modes were used for analysis. Acquisition of PPINICI data employed methane reagent gas at 1660-1690 mTorr (indicated) pressure. The ion source and manifold temperatures were 150 and $70{ }^{\circ} \mathrm{C}$, respectively, for $\mathrm{Cl}$ and 170 and $70^{\circ} \mathrm{C}$, respectively, for $\mathrm{El}$. The electron energy for $\mathrm{Cl}$ experiments was $100 \mathrm{eV}$ and that for EI was $70 \mathrm{eV}$. The third quadrupole was scanned with a scan time of $1 \mathrm{~s}$ per scan for PPINCI (m/ z 50-650 for positive ions and $10-650$ for negative ions) and $0.5 \mathrm{~s}$ per scan for EI data ( $\mathrm{m} / \mathrm{z} 35-650)$. The filament emission current was set at $200 \mu \mathrm{A}$.

(48) Hunt, D. F.; Stafford, G. C.; Crow, F. W.; Russell, J. W. Anal. Chem. 1976 48, 2098-105. 


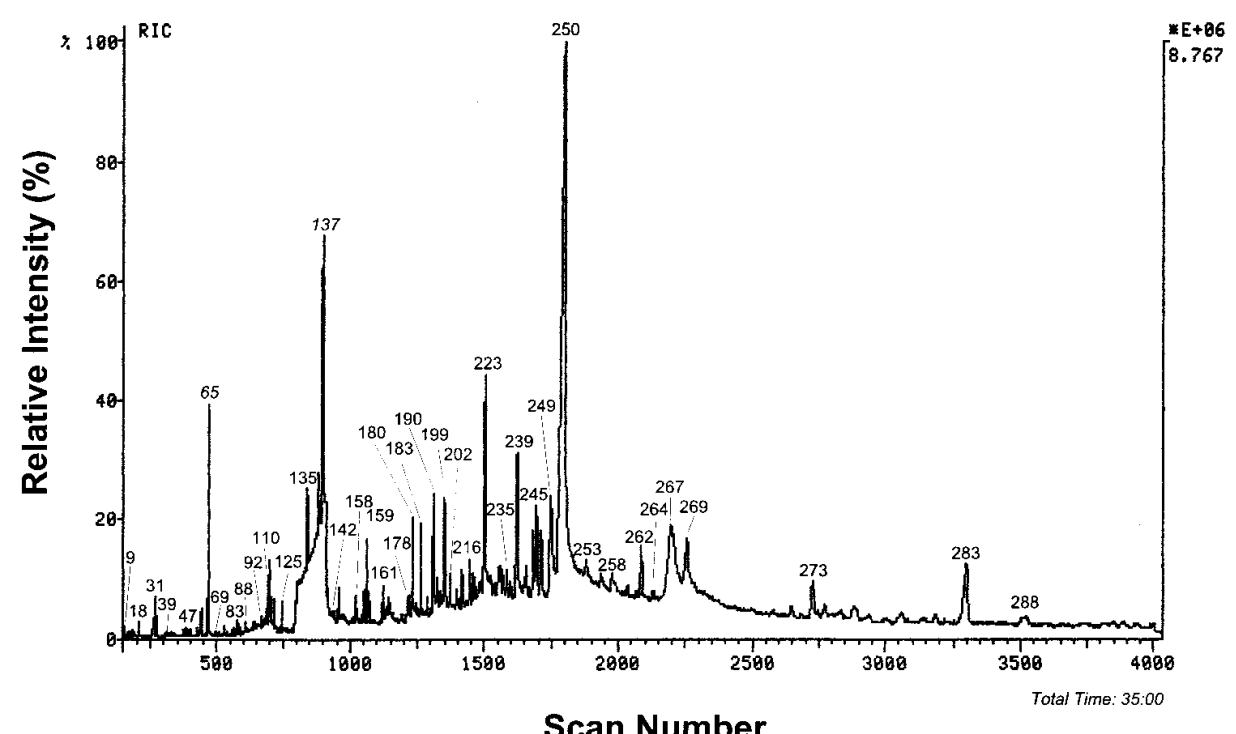

Figure 1. Reconstructed ion chromatogram from the El analysis of compounds thermally desorbed from five handled glass beads onto a HP5 GC column. Labeled peak numbers correspond to those listed in Table 1.

The conversion dynode was set at $-5 \mathrm{kV}$ for positive-ion $\mathrm{Cl}$ and $\mathrm{EI}$ and $+5 \mathrm{kV}$ for negative-ion $\mathrm{Cl}$. The electron multiplier was set between -1000 and $-1200 \mathrm{~V}$.

Prior to analysis on each day, the instrument was tuned with perfluorotributylamine (PFTBA) and GC/MS data for blanks (appropriate number of beads in an insert without rubbing) were recorded. Beads were selected randomly from a beaker containing clean beads. Beads were cleaned with multiple rinses of deionized water, methanol, and methylene chloride and baked out overnight before being reused. Prior to conducting the entire study of the four subjects, an insert was rubbed in a gloved hand to identify any possible compounds introduced from the gloves.

Tentative compound identifications were made by matching sample mass spectra with those of the NBS library for most of the peaks observed in the chromatograms. M anual interpretation was used for some of the identifications, and when available, standards were analyzed, as described earlier in this section.

\section{RESULTS AND DISCUSSION}

The Human Profile. A reconstructed ion chromatogram (RIC) of human skin emanations thermally desorbed from glass beads, acquired in EI mode, is presented in Figure 1. The peak numbers represent the elution order of identified peaks. Analysis using the methods employed here resulted in chromatograms that contained as many as 346 discernible peaks. Of these, 303 have been identified with varying degrees of certainty. Many of the more abundant components are labeled by number on the chromatogram. The peak numbers in Figure 1 correspond to those listed in Table 1.

In general, the four subjects studied were similar with respect to composition of emanations, with some exceptions discussed later in this manuscript. Further studies may reveal whether some of these are endogenous or if they are due to deposition on the skin from exogenous sources. Rigorous control of subject diet and exposure to exogenous sources was not performed. Although mosquitoes have little problem deciphering human odor cues amidst an odor profile with volatiles present that are exogenous to humans, the presence of these exogenous substances can complicate the discovery of host attractants. Previous publications have demonstrated the persistence (some cases 2 weeks or more) of exogenous substances, even when great care was taken in the sampling process. ${ }^{50,51}$

Forty-three of the detected component peaks in these analyses could not be classified nor identified from their $\mathrm{EI}$ and $\mathrm{Cl}$ mass spectra; these are not listed in Table 1. Some of the components detected in these analyses raised interesting problems in terms of identification or were not expected to be from a human subject; a few of these are discussed below.

Carboxylic Acids, Alcohols, and Esters of Carboxylic Acids. The majority of the intense peaks observed in the chromatogram are carboxylic acids. M any of the later eluting intense peaks are esters of pentanedioic and hexanedioic acids. Free fatty acids are metabolites formed in the sebaceous glands, ${ }^{52-55}$ and a much greater amount result from bacterial activity, through hydrolysis of triglycerides into free fatty acids (FFAs) on the skin. ${ }^{56}$ Previous work has shown that $90-99 \%$ of FFAs on the living layer of skin are below $\mathrm{C}_{20}$ in chain length. ${ }^{57}$ Of the total FFAs, hexadecanoic and octadecanoic acids accounted for $75-82$ wt \% The monounsaturated FFAs consist mainly of $86 \% 9$-octadecenoic acid and 6-7\% 9-hexadecenoic acid. Greater than $95 \%$ of the diunsaturated acids is 9,12-octadecadienoic acid. The positional isomers for sites of unsaturation are mainly at the 9-position for

(49) Bonin, M . A.; Asley, D. L.; Cardinal, F. L.; M cCraw, J. M.; Patterson, D. G. J. Am. Soc. Mass Spectrom. 1992, 3, 831-41.

(50) Labows, J.; Preti, G.; Hoelzle, E.; Leyden, J.; Kligman, A. J. Chromatogr 1979, 163, 294-9.

(51) Kostelc, J. G.; Preti, G.; Zelson, P. R.; Tonzetich, J.; Huggins, G. R. J. Chromatogr. 1981, 226, 315-23.

(52) Nicolaides, N.; Levan, N. E.; Fu, H. C. J. Invest. Dermatol. 1968, 50, 18494

(53) Nicolaides, N.; Fu, H. C.; Rice, G. R. J. Invest. Dermatol. 1968, 51, 83-9.

(54) Downing, D. T.; Strauss, J. S.; Pochi, P. E. J. Invest. Dermatol. 1969, 53 322-7.

(55) Downing, D. T.; Strauss, J. S. J. Invest. Dermatol. 1974, 62, 228-44.

(56) Puhvel, S. M .; Reisner, R. M .; Sakamoto, M. J. Invest. Dermatol. 1975, 64, 406- 11 .

(57) Ansari, M. N. A.; Nicolaides, N.; Fu, H. C. Lipids 1970, 5, 838-45. 
Table 1. Compounds Present or Suspected of Being Present from Thermal Desorption of Human Skin Emanations from Handled Glass. This List Was Derived from Cryofocused GC/MS Analyses of Four Human Subjects

\begin{tabular}{|c|c|c|c|c|c|c|c|}
\hline compound & $\begin{array}{l}\text { identified } \\
\text { peak no. }\end{array}$ & notes $^{c}$ & $M_{r}^{b}$ & compound & $\begin{array}{l}\text { identified } \\
\text { peak no. }\end{array}$ & notesc & $M_{r}^{b}$ \\
\hline \multicolumn{8}{|c|}{ Carboxylic Acids } \\
\hline acetic acid & 26 & $\mathrm{~S}, 5,6$ & 60 & methyltetradecanoic acid & 233 & $\mathrm{C}$ & 242 \\
\hline 2-propenoic acid & 43 & $\mathrm{~S}, 6$ & 72 & methyltetradecanoic acid & 237 & $\mathrm{C}$ & 242 \\
\hline propanoic acid & 40 & $S, 5,6$ & 74 & pentadecanoic acid & 239 & $\mathrm{~S}, 5,6$ & 242 \\
\hline 2-butenoic acid & 69 & $\mathrm{~S}$ & 86 & 9-hexadecenoic acid & 249 & $\mathrm{~S}$ & 254 \\
\hline 2-methyl-2-butenoic acid & 72 & $\mathrm{C}$ & 100 & methylpentadecanoic acid & 246 & $\mathrm{C}$ & 256 \\
\hline 3-methyl-2-pentenoic acid & 81 & $\mathrm{C}$ & 114 & hexadecanoic acid & 250 & $\mathrm{~S}, 5,6$ & 256 \\
\hline 3-methylpentanoic acid & 89 & $\mathrm{C}$ & 116 & heptadecenoic acid & 255 & C & 268 \\
\hline hexanoic acid & 90 & $\mathrm{~S}, 6$ & 116 & methylhexadecanoic acid & 253 & $\mathrm{C}$ & 270 \\
\hline heptanoic acid & 109 & $\mathrm{~S}, 6$ & 130 & heptadecanoic acid & 258 & $\mathrm{~S}, 6$ & 270 \\
\hline octanoic acid & 139 & $\mathrm{~S}, 6$ & 144 & 11-phenoxyundecanoic acid & 292 & $A, E$ & 278 \\
\hline nonanoic acid & 158 & $\mathrm{~S}, 6$ & 158 & 9,12-octadecadienoic acid & 263 & $S^{M, L}$ & 280 \\
\hline decanoic acid & 161 & $\mathrm{~S}, 6$ & 172 & 9-octadecenoic acid & 267 & $\mathrm{~S}, 5$ & 282 \\
\hline undecanoic acid & 176 & $A, 6$ & 186 & methylheptadecanoic acid & 264 & C & 284 \\
\hline dodecanoic acid & 190 & $\mathrm{~S}, 6$ & 200 & octadecanoic acid & 269 & $\mathrm{~S}, 5,6$ & 284 \\
\hline methyldodecanoic acid & 205 & $\mathrm{C}$ & 214 & docosanoic acid & 295 & & 340 \\
\hline tridecanoic acid & 209 & $\mathrm{~S}, 6$ & 214 & lactic acid & 117 & $\mathrm{~S}, 2,5,6$ & 90 \\
\hline tetradecenoic acid & 217 & $\mathrm{C}$ & 226 & hexanedioic acid & 286 & $A, E$ & 146 \\
\hline methyltridecanoic acid & 220 & $\mathrm{C}$ & 228 & heptanedioic acid & 291 & $A, E$ & 160 \\
\hline tetradecanoic acid & 223 & $\mathrm{~S}, 6$ & 228 & benzoic acid & 142 & $\mathrm{~S}, 6$ & 122 \\
\hline pentadecenoic acid & 238 & $\mathrm{~B}$ & 240 & 4-hydroxybenzoic acid & 152 & $\mathrm{C}$ & 138 \\
\hline methyltetradecanoic acid & 232 & $\mathrm{C}$ & 242 & 4-hydroxy-3-methoxybenzoic acid & 221 & $\mathrm{~B}$ & 168 \\
\hline \multicolumn{7}{|c|}{ Alcohols } & 184 \\
\hline 3-methyl-4-penten-2-ol & 42 & $B, C$ & 100 & tridecanol & 189 & $A$ & 200 \\
\hline 2-hexen-1-ol & 59 & $\mathrm{C}$ & 100 & 1-tetradecanol & 210 & $C, 5$ & 214 \\
\hline 4-hexen-1-ol & 56 & $\mathrm{C}$ & 100 & 2-hexadecanol & 245 & $C,(5 ?)$ & 242 \\
\hline 1-hexen-3-ol & 60 & $C,(1 ?)$ & 100 & 2-heptadecanol & 254 & $B, C$ & 256 \\
\hline 2-methyl-3-pentanol & 62 & $\mathrm{~B}, \mathrm{C}$ & 102 & cholest-5-en-3-ol & 303 & $\mathrm{~S}, 6$ & 386 \\
\hline 1-hepten-3-ol & 83 & & 114 & phenol & 110 & $S, 5,6$ & 94 \\
\hline 1 -octen-3-ol & 111 & $A, D$ & 128 & benzyl alcohol & 125 & $S, 5,6$ & 108 \\
\hline 2-octen-1-ol & 102 & $C$ & 128 & phenylethyl alcohol & 141 & $A, E, 5$ & 122 \\
\hline 2-methyl-3-octenol & 120 & $\mathrm{~B}, \mathrm{C}$ & 142 & 2-(2H-benzotriazol-2-yl)-4-methylphenol & 260 & $A, D$ & 225 \\
\hline nonenol & 134 & $\mathrm{C}$ & 142 & ethylene glycol & 112 & $\mathrm{~S}, 2,6$ & 62 \\
\hline 3,7-dimethyl-6-octen-1-ol & 144 & $\mathrm{~B}, \mathrm{C}$ & 156 & glycerol & 131 & $\mathrm{~S}, 6$ & 92 \\
\hline decenol, substituted & 153 & $\mathrm{D}$ & 156 & 2-(hydroxymethyl)-2-methyl-1,3-propanediol & 96 & $A, E$ & 120 \\
\hline 2-decanol & 155 & $\mathrm{~S},(5 ?)$ & 158 & & & & \\
\hline \multicolumn{8}{|c|}{ Aldehydes } \\
\hline propanal & 6 & $\mathrm{~S}, 2,6$ & 58 & nonanal & 135 & $\mathrm{~S}, 5$ & 142 \\
\hline 2-methylpropanal & 12 & 6 & 72 & 3,7-dimethyl-2,6-octadienal & 133 & $\mathrm{~B}, \mathrm{C}$ & 152 \\
\hline 2-methyl-2-butenal & 23 & $\mathrm{~B}, \mathrm{C}$ & 84 & decanal & 157 & $\mathrm{~B}, 5$ & 156 \\
\hline 2-methylbutanal & 31 & $C, 6$ & 86 & dodecanal & 171 & $\mathrm{~B}$ & 184 \\
\hline 3-methylpentanal & 49 & $\mathrm{C}$ & 100 & 2-methylhexadecanal & 213 & $A, B$ & 254 \\
\hline heptanal & 88 & $\mathrm{~S}, 2,5$ & 114 & benzaldehyde & 106 & $\mathrm{~S}, 5$ & 106 \\
\hline 2,2-dimethylhexanal & 103 & $C,(2 ?)$ & 128 & 3-hydroxy-4-methylbenzaldehyde & 132 & $\mathrm{~B}$ & 136 \\
\hline octanal & 108 & $\mathrm{~B}, 5$ & 128 & 4-phenylmethoxybenzaldehyde & 243 & A & 212 \\
\hline 2,4-nonadienal & 113 & $\mathrm{C}$ & 138 & & & & \\
\hline \multicolumn{8}{|c|}{ Aliphatics/ Aromatics } \\
\hline pentene & 14 & $\mathrm{~B}$ & 70 & 2-methyl-2-undecene & 124 & $\mathrm{D}, \mathrm{E}$ & 168 \\
\hline 4-methyl-2-pentene & 17 & $C,(2 ?)$ & 84 & 3-methyl-5-undecene & 123 & $\mathrm{D}, \mathrm{E}$ & 168 \\
\hline hexane & 19 & $\mathrm{~S}, 1,2,3$ & 86 & 4-methyl-4-undecene & 119 & $\mathrm{~B}, \mathrm{C}$ & 168 \\
\hline dimethylpentadiene & 24 & $B, C$ & 96 & 2-methyl-2-dodecene & 145 & C & 182 \\
\hline 2-methyl-1-hexene & 33 & $\mathrm{C}$ & 98 & methyldodecene & 147 & C & 182 \\
\hline heptane & 35 & $B, 1,2,3$ & 100 & tetradecene & 163 & $\mathrm{C}$ & 196 \\
\hline 3-ethyl-1,4-hexadiene & 45 & $A, B,(2 ?)$ & 110 & cyclotetradecane & 214 & $\mathrm{E}$ & 196 \\
\hline 2-methyl-1-heptene & 46 & C & 112 & tetradecane & 172 & $B$ & 198 \\
\hline 2-octene & 55 & 2 & 112 & pentadecane & 181 & $\mathrm{~S}$ & 212 \\
\hline 3-octene & 54 & & 112 & hexadecene & 196 & $\mathrm{D}, \mathrm{E}$ & 224 \\
\hline 4-octene & 53 & & 112 & cyclohexadecane & 240 & $\mathrm{E}$ & 224 \\
\hline 2,4-dimethylhexane & 57 & $C,(1 ?),(2 ?)$ & 114 & hexadecane & 197 & $\mathrm{~S}$ & 226 \\
\hline octane & 58 & $\mathrm{~S}, 1,5$ & 114 & heptadecane & 215 & $\mathrm{~S}, 5$ & 240 \\
\hline 3,4-nonadiene & 63 & C & 124 & 9-octadecene & 226 & $\mathrm{C}$ & 252 \\
\hline 2,6-dimethyl-1-heptene & 61 & $\mathrm{~B}, \mathrm{C},(1 ?)$ & 126 & methylheptadecane & 229 & $\mathrm{C}$ & 254 \\
\hline 4-ethyl-3-heptene & 80 & $B, C$ & 126 & octadecane & 230 & $\mathrm{~S}, 5$ & 254 \\
\hline 4-nonene & 85 & $C,(2 ?)$ & 126 & trimethyl-3-methylenehexadecane & 248 & $A, B$ & 272 \\
\hline nonane & 87 & $S, 1,5$ & 128 & heneicosane & 259 & & 296 \\
\hline $\mathrm{N}$-menth-6-ene & 127 & A & 138 & docosane & 271 & $\mathrm{~S}, 5$ & 310 \\
\hline menthane & 130 & A & 140 & tricosane & 274 & 5 & 324 \\
\hline trimethyl-1,5-heptadiene & 74 & $D, E$ & 138 & tetracosane & 287 & $A, 5$ & 338 \\
\hline 2,7-dimethyl-1-octene & 84 & $A, E$ & 140 & pentacosane & 297 & & 352 \\
\hline 5-decene & 101 & $C,(2 ?)$ & 140 & cholesta-3,5-diene & 301 & $A, B$ & 392 \\
\hline decane & 114 & $\mathrm{~S}, 2,5,6$ & 142 & triacontene, branched & 300 & $C^{2}$ & 410 \\
\hline undecadiene & 115 & $B$ & 152 & squalene & 299 & $\mathrm{~S}, 4,6$ & 410 \\
\hline
\end{tabular}




\section{Table 1 (Continued)}

compound

benzene

toluene

styrene

1,4-dimethylbenzene

propanamide

$\mathrm{N}, \mathrm{N}$-diethyl-3-methylbenzamide (DEET)

$\mathrm{N}, \mathrm{N}$-bis (2-hydroxyethyl)dodecanamide

$\mathrm{N}, \mathrm{N}$-didodecyl formamide

1,3-butanediamine

$\mathrm{N}, \mathrm{N}$-dimethyl-1,2-ethanediamine

$\mathrm{N}$-ethylcyclopentamine

$\mathrm{N}, \mathrm{N}$-dimethyl-3-butoxypropylamine

$\mathrm{N}, \mathrm{N}$-dimethyl-3-benzyloxypropylamine

2-butenoic acid, butyl ester

butanoic acid, methyl ester

nonanoic acid, methyl ester

tridecanoic acid, methyl ester

13-methylpentadecanoic acid, methyl ester

14-methylpentadecanoic acid, methyl ester

methylhexadecanoic acid, methyl ester

heptadecanoic acid, methyl ester

octadecenoic acid, methyl ester

hexadecanoic acid, methyl ester

16-methylheptadecanoic acid, methyl ester

octadecanoic acid, methyl ester

hexadecanoic acid, butyl ester

octadecanoic acid, phenyl ester

tetradecanoic acid, undecyl ester

methyl iodide

1-chlorohexane

1-chloroheptane

1-chlorononane

1-chlorododecane

1-chlorotetradecane

1-chloropentadecane

2-methyl-1H-pyrrole

3-methyl-1H-pyrrole

pyridine

3-pyridinamine

4-pyridinamine

4-methyl-2-pyridinamine

2-methylpyridine

$4(1 \mathrm{H})$-pyridinone

6-amino-3-pyridine carboxylic acid

3(1-methyl-2-pyrrolidinyl)pyridine (nicotine)

1,2,3-4-tetrahydroquinoline

2,3,4-trimethylquinoline

2-ethylpiperidine

1-piperidineethanol

4-piperidinemethanamine

1-phenyl-3-(1-piperidinyl)-2-buten-1-one

$1 \mathrm{H}$-indole

indole, substituted

4,5-dihydro-2-methyl-1H-imidazole

1,5-dimethyl-1H -pyrazole

pyrazine

2,6-dimethylpyrazine

butanone

2-pentanone

3-pentanone

2-hexanone

6-methyl-3,5-heptadien-2-one

6-methyl-5-hepten-2-one

carbon disulfide

identified

peak no. ${ }^{a}$

notes ${ }^{c}$

$M_{r}^{b}$

compound

identified

peak no. ${ }^{\mathrm{a}}$ notes ${ }^{\mathrm{c}} \quad \mathrm{M}_{\mathrm{r}}^{\mathrm{b}}$

Aliphatics/ Aromatics (Continued)

$\mathrm{S}, 1,2,3,6 \quad 78$ ethylbenzene

$\mathrm{S}, 1,2,3,6 \quad 92$ propylbenzene

S,2,3 $\quad 104 \quad 4,4^{\prime}$-dimethyl-1,1'-biphenyl

C, $1,2,3,5 \quad 106$

$\begin{array}{rll}78 & 1,2,3 & 106 \\ 104 & (1 ?) & 120 \\ 228 & \mathrm{~A} & 182\end{array}$

Amides/Amines/Related

198

185
285

22

5

219

167
170

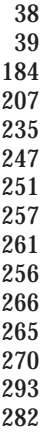

38
39
184
207
235
247
251
257
261
256
266
265
270
293
282

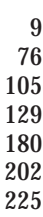

73

48
67

66

95
79

79
70

201
166

166

203

122

97

195

289

191

227

94

143

44
93

93

11

34

30

36
82

107

10

C

$73 \mathrm{~N}$-methyl-N-nitroso-1-dodecanamine

191 N,N-dimethyl-1-dodecanamine

$\begin{array}{lll}\text { A,E } & 287 & \text { N,N-dimethyl-1-tridecanamine } \\ \text { B } & 381 & \text { N,N-dimethyl-1-tetradecanamine }\end{array}$

$\begin{array}{lrl}\text { B } & 381 & \text { N,N-dimethyl-1-tetradecanamine } \\ \text { B } & 84 & \text { N,N-dimethyl-1-pentadecanamine }\end{array}$

D,E $\quad 116$ N,N-dimethyl-1-hexadecanamine

$113 \mathrm{~N}$ N-dimethyl-1-heptadecanamine

A $\quad 159 \mathrm{~N}, \mathrm{~N}$-dimethyl-1-octadecanamine

193

Esters

$\begin{array}{llllll}\text { A,(2?) } & 128 & \text { tetracosanoic acid, methyl ester } & 298 & A, B & 382\end{array}$

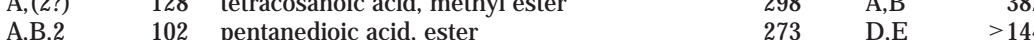

$\begin{array}{llllll}\text { A,B }, 2 & 102 & \text { pentanedioic acid, ester } & 273 & \text { D,E } & >144 \\ & 172 & \text { pentanedioic acid, mono(2-ethylhexyl) ester } & 276 & \text { C } & 244\end{array}$

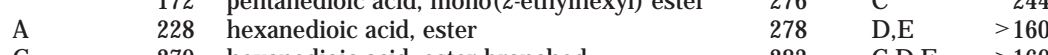

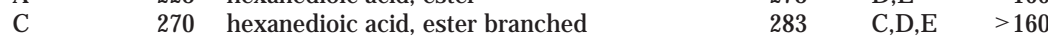

C 270 hexanedioic acid, mono(2-ethylhexyl) ester

284 hexanedioic acid, octyl ester

$\begin{array}{lll}\text { C } & 284 & \text { heptanedioic acid, dibutyl ester } \\ \text { C } & 296 & \text { hydroxybutanoic acid, ethyl ester }\end{array}$

270 3-hydroxybenzoic acid, methyl ester

C 298 4-hydroxybenzoic acid, propyl ester

B 298 2-hydroxybenzoic acid, phenylmethyl ester

312 2,4-dihydroxy-3,6-dimethylbenzoic acid,

C $P, E \quad 258$

$\begin{array}{lll}280 & \text { C } & 258 \\ 288 & B & 258\end{array}$

294 B 272

52 A 128

$178 \quad C \quad 152$

$204 \quad$ B,C $\quad 180$

242 A,E 196

$A, B \quad 382$

Halides/ Related

142 1-chlorohexadecane

120 1,6-dichloro-1,5-cyclooctadiene

134 benzylchloride

162 3-chlorobenzeneamine

204 2-chloro-1-methylethylbenzene

232 1-chloro-4-(4-methyl-4-pentyl) benzene

246 2,3-dichlorobenzeneamine

B Heterocyclics

(5?) 81 trimethylpyrazine

81 3-ethyl-2,5-dimethylpyrazine

S,5,6 $\quad 79$ 5-methyl-2-methylthio-4(1H)-pyrimidinone

94 1-methylpiperazine

94 2-ethylpiperazine

C 108 2,5-dimethylpiperazine

C,2,5 $\quad 93$ oxazole

95 2-methylfuran

B $\quad 138$ 3-methylfuran

4162 2,3-dihydro-4-methylfuran

171 benzofuran

(2?) $\quad 113$ dihydro-5-tetradecyl-2(3H)furanone

D,E $\quad 129$ 2,3-dihydro-3,5-dihydroxy-6-methyl-

A $\quad 114 \quad 4 H-p y r a n-4-o n e$

A 229 2-methoxy-6-methyl-4H -pyran-4-one

S,6 $\quad 117$ 2H-1-benzopyran-2-one

D >117 3-acetyl-6-methyl-2H-pyran-2,4(3H)dione

84 thiazolidine

C 96 2-methylisothiazole

80 5-methyl-2(5H)thiophenone

108 2-methoxy-5-methylthiophene

S,2,3,5,6 72 2-nonen-4-one

$5,2,5 \quad 86 \quad$ 2-decanone

S,2,6 $86 \quad$ 2-methoxy-2-octen-4-one

C

100 6,10-dimethyl-5,9-undecadien-2-one

124 3-hydroxyandrostan-11,17-dione

126

Sulfides

76 dimethyl disulfide

$\begin{array}{lll}241 & \text { B } & 260 \\ 160 & \text { B,D } & 176 \\ 118 & \text { S,6 } & 126 \\ 149 & \text { C } & 127 \\ 168 & \text { D } & 154 \\ 169 & \text { D } & 194 \\ 177 & \text { C } & 161\end{array}$

116 A 122

208 C $\quad 136$

212 A 156

121 C 100

$224 \mathrm{C} \quad 114$

$173 \quad \mathrm{C} \quad 114$

37
21

20

$15 \quad B, C,(5 ?) \quad 84$

75 (2?) 98

$13622 \quad 118$

$\begin{array}{lll}268 & \text { B } & 282 \\ 140 & \text { A } & 144\end{array}$

206 B

179 C 146

164 A 168

$211 \quad 89$

186 A 99

$162 \quad$ A,B $\quad 114$

$236 \quad C \quad 128$

138 B 140

$\begin{array}{lll}146 & \mathrm{~S} & 156\end{array}$

150 B,C 162

174 A 194

$3,5,6$

47 


\section{Table 1 (Continued)}

\section{compound}

thiomethane

2-thiopropane

1-methylthiobutane

1-thiododecane

3-methylthietane

3-(methylthio)-1,2-propanediol

urea

methylurea

1-isocyanato-3-methylbenzene

1,3-dimethoxybutane

methyl chloride

tetrachloroethene

1,1-difluoroethane

fluoroethene

1,1,2-trichloro-1,2,2-trifluoroethene

1-silacyclo-3-pentene

silacyclopentane

trimethylsilanol

hexamethylcyclotrisiloxane

octamethylcyclotetrasiloxane

decamethylcyclopentasiloxane

dodecamethylcyclohexasiloxane

tetradecamethylhexasiloxane

hexadecamethylcycloheptasiloxane

$$
\begin{aligned}
& \text { identified } \\
& \text { peak no. }
\end{aligned}
$$

notes $^{c} \quad M_{r}^{b}$

compound

identified
peak no. $^{\mathrm{a}}$ notes

\section{Thio/ Thioesters/ Sulfonyls}

\begin{tabular}{|c|c|c|c|}
\hline \\
\hline 4 & $2,5,6$ & 48 & o-(2-butenylthio)phenol \\
\hline $\begin{array}{r}50 \\
194\end{array}$ & C. (2?) & $\begin{array}{r}16 \\
104\end{array}$ & acetylthincarbamic acid methyl ester \\
\hline 188 & $D^{-12 i)}$ & 202 & $\begin{array}{l}\text { methanesulfonylchloride } \\
\text { mall }\end{array}$ \\
\hline 68 & A & 88 & $1,1^{\prime}$-sulfonylbis[4-chlorobenzene] \\
\hline 165 & D & 122 & \\
\hline & & & Urea/ Related \\
\hline 25 & 6 & 60 & thiourea \\
\hline 41 & 6 & 74 & N,N-dimethylthiourea \\
\hline & & & M iscellaneous \\
\hline 192 & B & 133 & 1,2,3-trimethoxypropane \\
\hline 126 & $A, E$ & 118 & 1,4-benzenedicarbonitrile \\
\hline & ompour & s Pre & ent in B ackground/ B lank Analyses \\
\hline 1 & 6 & 50 & 3-isopropoxy-1,1,1,7,7-hexamethyl-3,5,5- \\
\hline 7 & 3,5 & 164 & tris(trimethylsiloxy)tetrasiloxane \\
\hline 3 & $\mathrm{~S}$ & 66 & 2,4-bis(1,1-dimethylethyl)phenol \\
\hline 2 & & 46 & 2,5-bis(1,1-dimethylethyl)phenol \\
\hline 8 & & 167 & 2,4-bis(1,1-methylpropyl)phenol \\
\hline 27 & & 84 & 4,6-di(1,1-dimethylethyl)-2-methylphenol \\
\hline 28 & & 86 & 1,2-benzenedicarboxylic acid, diethyl ester \\
\hline 13 & & 90 & 1,2-benzenedicarboxylic acid, butylphenylmethyl ester \\
\hline 65 & & 222 & 1,2-benzenedicarboxylic acid, diheptyl ester \\
\hline 92 & & 296 & 1,2-benzenedicarboxylic acid, diisooctyl ester \\
\hline 137 & & 370 & 1,2-benzenedicarboxylic acid, bis(2-ethylhexyl ester) \\
\hline 159 & & 444 & 1,2-benzenedicarboxylic acid, diisononyl ester \\
\hline 187 & & 458 & 1,2-benzenedicarboxylic acid, undetermined ester \\
\hline 222 & & 532 & \\
\hline
\end{tabular}

$\begin{array}{rll}231 & \text { B } & 180 \\ 32 & \text { A,E } & 127 \\ 193 & \text { B } & 130 \\ 16 & & 114 \\ 272 & \text { B ,C } & 286\end{array}$

$\begin{array}{rrr}64 & 6 & 76 \\ 91 & & 104\end{array}$

156 A $\quad 134$

148 A 128

$182 \quad 576$

$\begin{array}{rlr}99 & \text { C,1,5 } & 206 \\ 98 & & 206 \\ 100 & & 206 \\ 151 & \text { B } & 220 \\ 200 & 5 & 222 \\ 277 & & 312 \\ 279 & & 362 \\ 284 & & 390 \\ 281 & & 390 \\ 290 & \text { A } & 418 \\ 286 & \text { D,E } & >415\end{array}$

a Peak numbers are assigned only to peaks identified wholly or partially and represent the elution order on an HP5 column. b Listed with each compound is the corresponding relative molecular mass $\left(M_{r}\right)$. ${ }^{c}$ Explanation of notes: $(S)$ Confirmed by comparison of retention time and/ or mass spectrum to that of the standard. (A) Identity of the compound is questionable, although the most reasonable identity is listed. The EI library search purity value is low (less than 750) either from the absence of characteristic masses in the sample mass spectrum or the presence of additional masses in the sample spectrum compared with the library spectrum. (B) The $\mathrm{Mr}_{\mathrm{r}}$ of this compound is known from $\mathrm{Cl}$ analysis. The actual structure given is questionable due to differences in fragmentation pattern of the library mass spectrum compared with the sample mass spectrum. (C) The structure is known to a reasonable degree of certainty. Uncertainty exists in the location of the substituted functional group and/ or in the double-bond location. (D) The class or base structure of this compound is characterized by a specific EI fragmentation pattern. The information from $\mathrm{Cl}$ may not be available to assist in determining the identity of this compound. (E) The $\mathrm{M}_{\mathrm{r}}$ from $\mathrm{Cl}$ analysis for this compound is questionable. (1) Reported previously in breath. ${ }^{34}$ (2) Reported previously as a volatile human effluent. ${ }^{39}$ (3) Reported previously as a volatile in human blood ${ }^{49}$ (4) Reported previously as a component of fingerprint residue 35 (5) Reported previously as a volatile human odor. 40 (6) Reported previously as a volatile human odor or present in effluent. ${ }^{36-38}$ (?) Compound reported previously is a different isomer of the listed compound.

hexadecenoic and octadecenoic acids, and 9,12- for octadecadienoic acid. These three compounds comprise greater than $90 \%$ of the unsaturated isomers, and all of the above-mentioned compounds are readily seen here. Although the method used in this paper is not amenable to the detection of hydroxy acids larger than L-lactic acid, there are $\alpha$-hydroxy acids on the skin, ranging from $\mathrm{C}_{14}-\mathrm{C}_{26}$, with $\mathrm{C}_{16}$ and $\mathrm{C}_{18}$ as the primary constituents. Internally branched FFAs were not detected, except possibly in the case of methyltetradecanoic acid; this is probably a result of the low sample volume collected combined with the low amount of these compounds present. Although the sensitivity was not adequate to provide information on trace levels of fatty acids, it is important to keep in mind that the method described herein involves little sample preparation and no concentration or cleanup steps. Lipids greater than 18 carbons in backbone chain length are less intense under the chromatographic conditions of this manuscript. These were condsidered less important because they are thought to be too involatile to factor into mosquito attraction.

Comprehensive discussions of all six series variations of FFAs can be found elsewhere. ${ }^{55,58,59}$ The primary fatty acids are straight-

(58) Nicolaides, N. Science (Washington, D.C.) 1974, 186, 19-26. chain, even-numbered carbon backbones, split approximately evenly between fully saturated and monounsaturated compounds. This series accounts for approximately $70 \%$ of the FFAs. Straightchain, odd-numbered carbon-backboned saturated and monounsaturated FFAs comprise another 10\% About 10\% contain an iso- methyl branch at the terminus opposite the acid moiety, while $3 \%$ have an anteiso- methyl branch three carbons in from the terminus opposite the acid functional group. Internally branched monomethyl fatty acids constitute $3 \%$ of FFAs, and the remaining $4 \%$ consists of diunsaturated straight-chain and dimethyl-branched FFAs. ${ }^{58}$ Inspection of Table 1 indicates that several methylbranched fatty acids were observed, and these are probably the iso- configurations, although additional effort was not made to identify the actual position of branching. There are three methylbranched tetradecanoic acid isomers observed; therefore, at least one of these has an internal methyl branch.

When the chromatography and recording of mass spectral information was continued past the final retention time of Figure 1, a series of fatty acid lipid esters was observed but is not presented here; these were baked off of the column between

(59) Nicolaides, N.; Apon, J. M. B. Biomed. Mass Spectrom. 1977, 4, 336-46. 
experiments. The pattern of carboxylic acid peaks in this chromatogram and many of the chromatograms acquired using these parameters appears to be similar to that observed from bacteria. ${ }^{43}$ Moreover, it is expected that some discrimination exists in this method against highly volatile, low relative molecular mass acids (as well as the more volatile compounds of other compound classes). Lactic acid, for example, was difficult to detect in EI mode while other hydroxy acids, such as tartaric acid, and oxo acids, such as pyruvic acid, were not detected by this method. Although not observed here, tartaric and pyruvic acids are known to be present in skin emanations. ${ }^{38}$

Numerous short-chain alcohols were observed, and most of these were unsaturated. Alcohols on the skin result from the reduction of FFAs present on the skin. ${ }^{58}$ Here is a contrast between the large number of unsaturated alcohols observed in this study and the absence of unsaturated alcohols in previous studies. 39,40 Unfortunately, the location of unsaturation and location of the alcohol moiety in most of these compounds remains uncertain. A known attractant for some species of mosquitoes, 1-octen-3-ol, 21 is identified tentatively here and has been noted as a skin emanation in a recent publication. ${ }^{60}$ There were two octenol isomers observed in this study, and one could possibly be 1-octen3-ol as noted in Table 1.

The relatively intense, saw-tooth-shaped peak located at a scan number between 800 and 900 in Figure 1 (retention time between 8 and $10 \mathrm{~min}$ ) presented an interesting problem with respect to identification, ironically because of the large amount of this compound present in the analysis. Because of the inability to locate a plausible mass-to-charge value for the molecular ion in the EI mass spectrum for this compound, a clue from the peak shape and relative molecular mass information from $\mathrm{PCl}$ and $\mathrm{NCl}$ were used to assist in the identification. The shape of this peak is similar to lactic acid (addressed below); thus, it was expected that this compound may also be a hydroxy acid or, at least, highly polar.

Visual inspection of $\mathrm{PCl}$ data revealed that a $\mathrm{M}_{\mathrm{r}}$ of 92 was plausible due to the abundance of the apparent $[\mathrm{M}+\mathrm{H}]^{+}$ion at $\mathrm{m} / \mathrm{z}$ 93. However, the $\mathrm{NCl}$ mass spectrum did not contain an abundant $[\mathrm{M}-\mathrm{H}]^{-}$ion at $\mathrm{m} / \mathrm{z} 91$. The $\mathrm{NCl}$ mass spectrum did contain an ion at $\mathrm{m} / \mathrm{z} 183$ which was postulated to be the $\left[\mathrm{M}_{2}-\right.$ $\mathrm{H}]^{-}$ion of this compound. When the library searching was restricted to compounds of $92 \mathrm{Da}$, a tentative identification of 1,2,3propanetriol (glycerol) was made. The mass spectra did not match well, but final confirmation was achieved by comparing the sample EI mass spectrum to that of a standard of glycerol introduced into the ion source via a direct-inlet probe. When the ion source was saturated under these conditions, it was demonstrated that formation of a proton-bound dimer by self-Cl had occurred, both here and previously, upon elution of glycerol during sample analyses. The presence of self-Cl-produced fragments of this peak in the EI mass spectrum of the analysis in Figure 1 did not permit successful library matching. The glycerol peak from all other subjects was at least two orders in magnitude smaller than the amount detected from this subject. It was later determined that the high glycerol level was attributable to the Sta-Sof-Fro hair and scalp spray used by this subject; glycerol is one of the primary ingredients in the product. This example is a clear case of a

(60) Cork, A.; Park, K. C. M ed. Vet. Entomol. 1996, 10, 269-76. substance of exogenous origin being introduced, or at least greatly increased in amount present, on the skin. A strict routine and abstinence from hygiene products would most likely have reduced the exogenous substances; however, some substances persist in excess of 2 weeks on the skin. ${ }^{50}$ This persistence and the difficulty with keeping volunteers on a strict identical routine make it difficult to perform an analysis without some exogenous compounds being present. Although this complicates the analysis by the addition of compounds that most likely have no effect on the host-seeking process of mosquitoes, the compounds of interest are still present and, except for the siloxanes discussed later and the above case of glycerol, in significantly greater amounts than exogenous substances.

A poorly chromatographed peak in these experiments was located approximately at scan 680 (retention time of $6 \mathrm{~min}$ ). The peak is typically one of the largest observed when examined in $\mathrm{PCl}$ and $\mathrm{NCl}$ modes, but fails to produce a significant peak in $\mathrm{EI}$ mode. Examination in $\mathrm{NCl}$ mode indicates that this peak is lactic acid due to its relative molecular mass and characteristic fragment ions. ${ }^{41}$ Lactones have been detected on the skin, ${ }^{40}$ although none are reported here. Some of these may constitute a portion of the 43 compounds that are still unidentified.

Aldehydes, Aliphatics, Aromatics, and Ketones. Chromatographic peaks for the aldehydes became more intense as the series progressed from propanal to nonanal, then became less intense. Some substituted aldehydes were observed. Although nonanal coeluted with glycerol on an HP5 column under the conditions described previously, it was readily identifiable due to its intensity. Curiously, butanal, hexanal, and undecanal were not observed in the described series which runs from propanal to dodecanal. These three aldehydes have not been observed in previous work on human effluents, ${ }^{39}$ but were observed in microscale purge and trap GC/ M S analysis of human emanations in our laboratory. ${ }^{41}$

There are numerous alkanes and alkenes present below decane and possibly others at levels too low for detection. Additionally, it is believed that some of these compounds were lost to rapid evaporation because of the high volatility of low relative molecular mass compounds. When samples were analyzed with a GC program ramped to a higher temperature and with a shorter column than reported here, both squalene and cholesterol were observed as intense peaks and they elute after octacosane and triacontane, respectively, on a DB-1 column. The analyses reported in this manuscript were typically ended just after pentacosane eluted.

B enzene, toluene, styrene, and some alkyl-substituted benzenes were found on handled beads. These have been reported elsewhere as being present in human breath and on human skin; 34,39 however, these are most likely exogenous. Additionally, dimethyl biphenyl is the best library match to peak 228; however, given the low purity value of the EI library search, this identity is questionable.

Few ketones were observed, with most of the ketone peaks attributed to those between butanone and decanone. A trace amount of hydroxyandrostandione was identified in one of the analyses, but the identity of this compound is also suspect. Acetone was not observed but is believed to be present during the handling of glass and then lost due to its high volatility. 


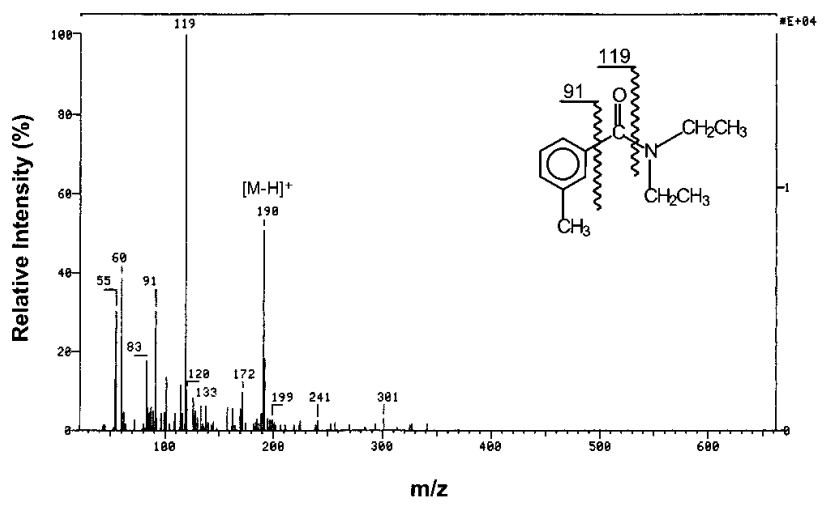

Figure 2. Electron ionization mass spectrum of the GC peak corresponding to $\mathrm{N}, \mathrm{N}$-diethyl-3-methylbenzamide (DEET). The mass spectrum is from an analysis of five handled glass beads.

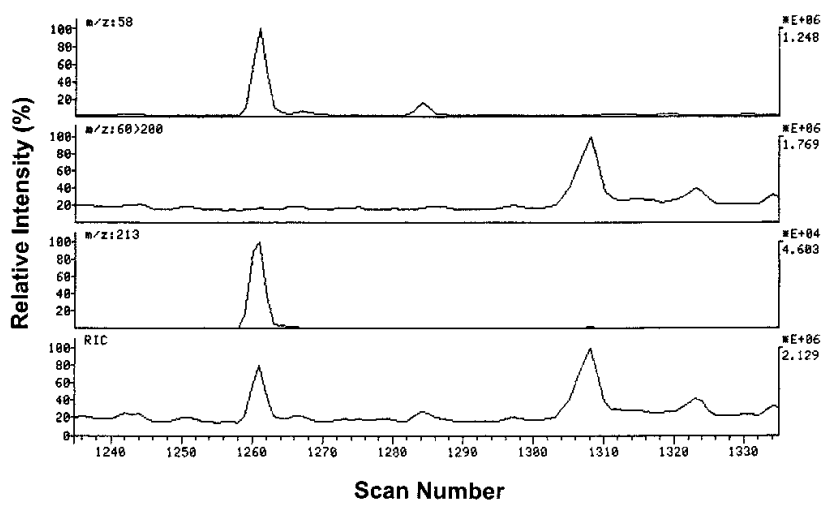

Figure 3. Mass chromatograms of (a) $m / z 58$, (b) $m / z 60-200$, (c) $\mathrm{m} / \mathrm{z} 213$, and (d) the reconstructed ion chromatogram for the GC peak (scan 1261) corresponding to $\mathrm{N}, \mathrm{N}$-dimethyl-1-dodecanamine. The chromatograms are from an El analysis of three handled glass beads.

Amides, Amines, and Heterocycles. Very few amides were found in the samples. The identification of N,N-diethyl-3-methylbenzamide (DEET) on the skin of some of the subjects was unexpected and certainly of exogenous origin. Three of the four subjects were involved in routine tests involving topical application of DEET to the skin. Therefore, it is plausible that residual DEET on the skin remained after repeated washing and was transferred to the glass beads. An accurate account of the persistence of this chemical is not possible, but it is believed that tests were conducted with DEET during the week prior to the attractant emanation study. This equates to DEET being detectable by the method employed herein for 3-8 days after application on the skin. The El mass spectrum for this identified compound from an analysis of one of the human subjects is presented in Figure 2.

A homologous series of tertiary amines was observed in some of the samples from subjects, spanning from N,N-dimethyl-1dodecanamine to $\mathrm{N}, \mathrm{N}$-dimethyl-1-octadecanamine. Some of these amines eluted at retention times near those of similarly structured carboxylic acids, and their peaks were often hidden under the more abundant acids. Examination of El reconstructed ion chromatograms showed only two significant ions were present (Figure 3). These ions were the base peak at $\mathrm{m} / \mathrm{z} 58$ (due to $\alpha$ cleavage of the chain) and the corresponding odd-mass molecular ion in the mass spectrum of Figure 4. Library matching initially did not provide the correct identity for most of these homologous

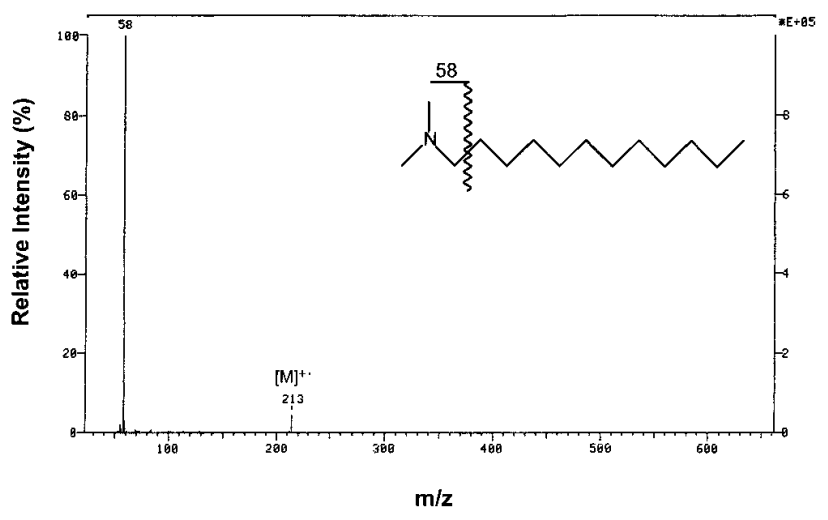

Figure 4. Electron ionization mass spectrum of the GC peak corresponding to $\mathrm{N}, \mathrm{N}$-dimethyl-1-dodecanamine. The mass spectrum is from an analysis of three handled glass beads.

amines. Upon inspection of library mass spectra for suspected amines, it was determined that in addition to the 12-carbon or greater chain, substitutions of anything larger than methyl groups on the nitrogen would result in a base peak of higher mass-tocharge value in the mass spectrum. Once the proper restrictions were imposed on the library search, identifications of these amines were achieved readily for this series. Evidence for the endogenous or exogenous origin of these long-chain amines does not exist.

$M$ any heterocyclic structures were observed. Substituted pyrroles, pyridines, piperidines, pyrazines, piperazines, and furans were detected in this study and are believed to be of human origin. ${ }^{39}$ Pyridines and methylpyridines have been found to be elevated in the breath of subjects with periodontal disease. ${ }^{61} \mathrm{An}$ interesting finding was the presence of nicotine, al beit a low level, on beads handled by some subjects. It is possible that these may be related to tobacco use, rather than being deposited on skin from exogenous sources; however, there are insufficient data to support or refute this in this case. Nicotine has been observed on the skin in previous studies. ${ }^{35}$

Halides, Sulfur-Containing, and Urea-Related Compounds. In addition to the observation of methyl iodide, which could not be accounted for as background, other haloalkanes were observed. An incomplete series of chloroalkanes from chlorohexane to chlorohexadecane was observed. Some of these chloroalkanes were reported previously in human breath. ${ }^{34}$

It is expected that breath contains relatively higher amounts of malodorous sulfides than are present on the skin. ${ }^{61}$ Several sulfides are produced by bacteria and known to be endogenous. $34,40,61$ Carbon disulfide and dimethyl disulfide were readily observed in this study, while dimethyl trisulfide is not listed here because it was only observed using purge and trap analysis. A few mercaptans, such as thiomethane and 2-thiopropane, are also present, as is urea.

Miscellaneous and Background Compounds. Some residual halides and chlorofluorocarbons were observed, but the background/ blank samples mainly consisted of siloxanes believed to come from the column stationary phase and phthalate contaminants. Siloxanes were identified readily in analyses of volatile

(61) Kostelc, J. G.; Preti, G.; Zelson, P. R.; Stoller, N. H.; Tonzetich, J. J. Periodontal Res. 1980, 15, 185-92. 
organic compounds in the cabin air of the Skylab spacecraft. ${ }^{62}$ These siloxanes are not expected to be endogenous. These two series of compounds dominated chromatograms from the analysis of blank beads. Hexamethylcyclotrisiloxane and octamethylcyclotetrasiloxane were often readily observed in sample analyses (see the italicized peak numbers 65 and 137 of Figure 1).

One component, 1,1-difluoroethane (Dust-Off), was introduced into the system because it was employed to cool the glass injection port liner between runs prior to introducing a sample. When the glass injection port liner was reinserted and the analysis conducted, latent difluoroethane eluted off of the column relatively early and was usually one of the most intense peaks. The retention time of this component was used, for qualitative purposes only, as a means to correlate some of the repetitions. This compound is not listed in the table since it was not introduced into the system via transfer from the skin to glass beads.

\section{CONCLUSIONS}

The compounds present on skin were similar among the human subjects, but the relative amounts of many compounds differed between subjects. This was expected since skin lipids were already known to be very similar for all humans. Observations based on these experiments indicate that some compounds, one of which is L-lactic acid, in the emanations of a human, can vary in abundance by an order of magnitude on consecutive days. The abundance of other compounds, such as dodecanoic and tetradecanoic acids, tend to change little when compared on consecutive days.

A wide range of compound classes was identified, and some unexpected compounds which were observed and identified were later explained as being exogenous in origin. Exogenous compounds are expected to be the most difficult problem that will need to be overcome before meaningful results can follow from comparison of different subjects or comparison of the same subject over consecutive days.

(62) Liebich, H. M .; Bertsch, W.; Zlatkis, A.; Schneider, H. J. Aviat. Space Environ. M ed. 1975, 46, 1002-7.
At least 346 distinct peaks were detected by cryofocused GC/ MS analyses. Of the compound peaks detected, 43 were unidentified while 303 were identifed by standard or identified tentatively by library and spectral interpretation. There were 26 compounds confirmed to be of background origin, leaving 277 compounds as candidate attractants for Ae. aegypti. The number of compounds observed makes for a difficult and tedious bioassay process. Even with such a large number, there is no guarantee that all of the important compounds have been detected, and it is strongly believed that they have not been.

The next phase of this work will focus upon an approach to more selectively determine candidate volatiles that may be factors in mosquito attraction. Experiments will be performed to compare skin emanations between two subjects that differ markedly in attraction, to compare day to day variations in emanations, to correlate these to attraction measured by bioassay and, on the basis of knowledge that handled glass remains attractive less than $6 \mathrm{~h}$, to identify compounds that are decreased significantly after $6 \mathrm{~h}$ of storage on glass beads.

\section{ACKNOWLEDGMENT}

The authors thank Dan Smith and Ken Posey of the USDA for serving as volunteer subjects by handling glass beads for these experiments. Constructive suggestions and criticisms on an earlier version of this manuscript by Dr. James Stephenson, Jr., Dr. Casey Grimm, and Dr. George Preti are greatly appreciated. Dr. Preti deserves additional thanks for the time that was spent discussing the origin of exogenous compounds observed in analyses of this type and indicating key work performed previously. Funding for this work was supplied by the M osquito \& Fly Research Unit at the USDA-ARS-CMAVE under a specific cooperative research grant (no. 58-6615-6-021).

Received for review August 24, 1999. Accepted November 12, 1999.

\section{AC990963K}

